\title{
Synthesis of a magnetic C@Co material via the design of a MOF precursor for efficient and selective adsorption of water pollutants
}

Yu Liu

College of Science, Shenyang University of Chemical Technology

\section{Yan Wang}

College of Science, Shenyang University of Chemical Technology

\section{Xiao-Sa Zhang}

College of Science, Shenyang University of Chemical Technology

\section{Wen-Ze Li}

College of Science, Shenyang University of Chemical Technology

\section{Ai-Ai Yang}

College of Science, Shenyang University of Chemical Technology

Jian Luan ( $2010044 @ s t u . n e u . e d u . c n$ )

Northeastern University https://orcid.org/0000-0002-3851-0829

Hong-Zhu Liu

Post-Doctoral Research Station of Dalian Zhenbang Fluorocarbon Paint Stock Co., Ltd

\section{Zhong-Gang Wang}

Dalian University of Technology

\section{Research Article}

Keywords: MOF precursor, Magnetic C@Co material, Selective adsorption, Kinetics and thermodynamics

Posted Date: September 15th, 2021

DOl: https://doi.org/10.21203/rs.3.rs-888378/v1

License: (c) (i) This work is licensed under a Creative Commons Attribution 4.0 International License. Read Full License

Version of Record: A version of this preprint was published at Journal of Inorganic and Organometallic Polymers and Materials on November 22nd, 2021. See the published version at https://doi.org/10.1007/s10904-021-02157-0. 


\section{Abstract}

3D metal-organic frameworks (MOFs) can be appropriate templates for the fabrication of nanomaterials due to they have active sites exposed on the channel or surface, which thus provide them with improved catalytic performance. In this study, a 3D cobalt-based MOF [Co $\left(\mathrm{H}_{2} \text { bpta) }\right]_{n}$ (Co-MOF), where $\mathrm{H}_{4}$ bpta denotes 2,2',4,4'-biphenyltetracarboxylic acid, has been constructed with the use of a ligand with a high carbon content. On this basis, a 2D magnetic carbon-coated cobalt nanoparticle composite (C@Co) was prepared by using the title MOF. Magnetic C@Co can readily absorb dye from the solution and can thus act as an inexpensive and fast-acting adsorbent. Moreover, we have explored the adsorption isotherms, kinetics and thermodynamics of the anion dyes in detail. The adsorption capacity of the C@Co for investigated methyl orange (MO) and congo red (CR) dyes were 773.48 and $495.66 \mathrm{mg} \mathrm{g}^{-1}$, respectively. It is noteworthy that $\mathrm{MO}$ adsorption is higher in existing materials. Thermodynamic studies suggest that the adsorption processes are spontaneous and exothermic. This study opens a new insight into the synthesis and application of carbon-based materials that enable the selective removal of organic dyes.

\section{Introduction}

With the growth of the printing, textile, and other industries in recent years, the discharge of dye wastewater has increased each year. ${ }^{1-4}$ Methyl orange (MO) and Congo red (CR) are two common anionic dyes which have been widely used in the industries and research laboratories. ${ }^{5,6}$ Nowadays, a variety of methods such as oxidation, ozonation or degradation have been exploited to remove anionic dyes from wastewater. ${ }^{7-10}$ However, aforementioned techniques have poor selectivity and are relatively expensive because they cannot be reused. Therefore, there is an urgent need for an efficient way to selectively remove anionic dyes.

Carbon-based materials are regarded as ideal candidates for the adsorption heavy metal ions and organic pollutants because of their good stabilities and high specific surface areas. ${ }^{11-14}$ However, these materials have only offered modest anionic dye removal performance. ${ }^{15-18}$ Therefore, achieving selective, efficient, and reversible anionic dye adsorption and desorption using a carbon-based material continues to pose a daunting challenge.

Metal-organic frameworks (MOFs) as sacrificial precursors or templates for preparing highly dispersed inorganic, organometallic, and composite materials with good stabilities and high specific surface areas after the calcined or pyrolysis process have been widely used. ${ }^{19-22}$ Notably, MOF-derived materials can remain the original morphologies of the MOFs under appropriate conditions. Among them, Co-doped carbon-based materials synthesized by the pyrolysis of Co-containing MOF precursors are considered as good adsorbents. ${ }^{23-26}$ Carbon-coated cobalt composites (C@Co) have been regarded as adsorbents for the removal of organic and inorganic pollutants from solutions, and they have been found to offer performances comparable to commercial adsorbents. ${ }^{27-31}$ Furthermore, the outstanding adsorption capabilities of C@Co relative to other adsorbents may be caused by strong interactions between C@Co 
and the targeted compounds through $\pi-\pi$ interactions, which result from the presence of delocalized electrons in hexagonal arrays of carbon atoms that thus facilitate adsorption onto the surfaces of C@Co materials. $^{32,33}$

In this work, $\left[\mathrm{Co}\left(\mathrm{H}_{2} \text { bpta) }\right]_{\mathrm{n}}\right.$ (Co-MOF), where $\mathrm{H}_{4}$ bpta denotes 2,2',4,4'-biphenyltetracarboxylic acid, was synthesized under solvothermal conditions (Tables S1 and S2). The Co-MOF was thermally annealed under an $\mathrm{N}_{2}$ atmosphere to form carbon-based composites (C@Co) (Scheme 1). The dye adsorption performances of the Co-MOF and C@Co have been studied. Moreover, the kinetics and thermodynamics parameters of the dye adsorption on the C@Co were investigated in detail to gain insight regarding the adsorption mechanism.

\section{Experimental Section.}

\subsection{Materials and Methods.}

The ligand 2,2',4,4'-biphenyltetracarboxylic acid $\left(\mathrm{H}_{4} \mathrm{bpta}\right)$ was synthesized by the methods described in the literature. ${ }^{34}$ All other reagents and solvents were reagent grade, which employed from commercial sources and used without further purification.

\subsection{Synthesis of $\left[\mathrm{Co}\left(\mathrm{H}_{2} \mathrm{bpta}\right)\right]_{n}(\mathrm{Co}-\mathrm{MOF})$.}

A mixture of $\mathrm{CoCl}_{2} \cdot 6 \mathrm{H}_{2} \mathrm{O}(0.048 \mathrm{~g}, 0.2 \mathrm{mmol}), \mathrm{H}_{4}$ bpta $(0.052 \mathrm{~g}, 0.15 \mathrm{mmol}), \mathrm{CH}_{3} \mathrm{CN}(3 \mathrm{~mL})$, and $\mathrm{H}_{2} \mathrm{O}(3$ $\mathrm{mL}$ ) were placed in a $20 \mathrm{~mL}$ Teflon-lined autoclave and kept at $120^{\circ} \mathrm{C}$ for $96 \mathrm{~h}$. Then, it was cooled to room temperature and obtained purple cubic crystals of $\left[\mathrm{Co}\left(\mathrm{H}_{2} \mathrm{bpta}\right)\right]_{\mathrm{n}}$. $(0.064 \mathrm{~g}, 58 \%$ yield based on $\mathrm{Co})$. Calcd for $\mathrm{C}_{16} \mathrm{H}_{8} \mathrm{CoO}_{8}$ (\%): C, 48.33; $\mathrm{H}, 2.52$. Found (\%): C, 48.25; H, 2.24. FT-IR $\left(\mathrm{KBr}, \mathrm{cm}^{-1}\right): 3437(\mathrm{~m}), 2395$ (m), 1905 (w), 1619 (s), 1572 (s), 1559 (s), 1416 (s), 1370 (s), 1244 (s), 1131 (m), 805 (w), 696 (s).

\subsection{Synthesis of the carbon-based composites of [Co( $\left.\left.\mathrm{H}_{2} \mathrm{bpta}\right)\right]_{\mathrm{n}}$ (C@Co).}

Firstly, the Co-MOF complex was placed in a quartz boat and situated in a tubular furnace. Secondly, the furnace temperature was increased to $800^{\circ} \mathrm{C}$ under the $\mathrm{N}_{2}$ flow $(200 \mathrm{~mL} / \mathrm{min}, 99.999 \%$ purity) with the heating rate of $20^{\circ} \mathrm{C} \mathrm{min}^{-1}$. Thirdly, the carbon-based material was prepared with $\mathrm{N}_{2}\left(200 \mathrm{~mL} \mathrm{~min}{ }^{-1}\right)$ for 60 min. Finally, it was cooled to room temperature with $\mathrm{N}_{2}$ flow, the carbon-based material had been synthesized.

\subsection{Characterization.}

The elemental analyses $(\mathrm{C}, \mathrm{H}$, and $\mathrm{N})$ of the samples were performed with a Perkin-Elmer $240 \mathrm{C}$ elemental analyzer. FT-IR spectra ( $\mathrm{KBr}$ pellets) were recorded with a Varian 640-IR spectrometer over the spectral from 500 to $4000 \mathrm{~cm}^{-1}$. Powder X-ray diffraction (PXRD) data was collected using a Rigaku diffractometer with CuKa radiation. Meanwhile, the morphology of the carbon-based material was 
characterized via scanning electron microscopy (SEM, Nova Nano SEM 430) and high-resolution transmission electron microscopy (HRTEM, JEOL2010 at $200 \mathrm{kV}$ ). The thermal stabilities of Co-MOF and the carbon-based composite of C@Co were measured with a thermogravimetric analyzer (NETZSCH STA 449C). The specific surface area and pore structure of C@Co was measured by an automatic volumetric sorption analyzer (ASAP $2020 \mathrm{M}$ ) using $\mathrm{N}_{2}$ as the adsorbate at $-196^{\circ} \mathrm{C}$. UV-Vis absorption spectra were recorded using an SP-1900 UV-Vis spectrophotometer.

\section{Results And Discussion}

\subsection{Preparation and characterization of the cobalt-coated carbon-nanoparticle composite (C@Co).}

It should be noted that the Co-MOF is the same that had been reported previously by Pan and coworkers. ${ }^{35}$ According to reported research, the MOF-derived carbon-based materials could improved the energy conversion and storage capabilities as well as the adsorption properties of the resultant composite materials. ${ }^{36}$ As a result, researchers have investigated the in situ growth carbon-based composites using MOFs as precursors, which is an efficient strategy for enhancing the properties of the MOF-derived materials. ${ }^{37,38}$ On this basis, the C@Co was synthesized via the chemical vapor deposition (CVD) method with the use of Co-MOF as a precursor. The morphology of the C@Co was observed by SEM and TEM characterization. After calcined, the Co-MOF formed Co nanoparticles, and the surrounding organic ligands were pyrolyzed into a Co-doped carbon skeleton which surrounded the nanoparticles. It can be seen that C@Co maintains a 2D layered structure, and Co particles are loading on the carbon surface (Fig. 1). The diameter of the Co particles is in the range of $30-40 \mathrm{~nm}$, and the Co nanoparticles in the carbon matrix are well dispersed without exhibiting significant agglomeration. The FT-IR spectrum of the C@Co was recorded in the frequency range of $500-4000 \mathrm{~cm}^{-1}$, as shown in Fig. 2a. The band at $3437 \mathrm{~cm}^{-1}$ corresponds to the stretching and bending vibrations of the hydroxyl groups of C@Co, while the peaks observed at $1653 \mathrm{~cm}^{-1}$ correspond to the asymmetric and symmetric vibrations of the carboxyl groups of C@Co.37,38 Moreover, we have investigated the thermal stability and the components in C@Co by thermogravimetric analysis (TGA) measurements in air at temperatures reaching up to $800^{\circ} \mathrm{C}$ (Fig. $2 \mathrm{~b}$ ), and found that the weight loss of C@Co occurred via a single step. This weight loss of $25 \%$ in the range of $220-310^{\circ} \mathrm{C}$ is the decomposition of amorphous carbon. Moreover, the residual catalyst content is $74 \%$ after oxidation, suggesting that the majority of the catalyst residue remains in the sample. The PXRD pattern of the C@Co material prepared via the calcine of Co-MOF is demonstrated in Fig. 2c. The materials show metallic $\mathrm{Co}$ and weak $\mathrm{CoO}$ and $\mathrm{Co}_{3} \mathrm{O}_{4}$ diffraction peaks, the latter two sets of peaks can be attributed to the oxidation of the surface Co nanoparticles undergoing oxidation in the air. ${ }^{39}$ Additionally, the cobalt particles gradually aggregate and separate from the carbon layer, then they are oxidized during the high temperature. Meanwhile, the C@Co sample has a specific surface area of 340.54 $\mathrm{m}^{2} \mathrm{~g}^{-1}$ and a pore size distribution from 2 to $10 \mathrm{~nm}$, suggesting that it possesses mesoporous structures 
(Fig. 2d). It is well known that the pores with variety of sizes is an appropriate way to increase active centers and can yield high-efficiency sorbents. ${ }^{40}$

\subsection{Dye adsorption properties of Co-MOF and C@Co.}

MOFs are excellent adsorbents and are generally used on account of their specific surface areas, diverse range of functional groups, and controllable channel sizes. ${ }^{41,42}$ Herein, the adsorption properties of dyes from wastewater brought about widespread attention. ${ }^{43,44}$ In this study, three cationic dyes [methylene blue (MB), rhodamine $B(\mathrm{RhB})$ and gentian violet (GV)] and two anionic dye (MO and $\mathrm{CR}$ ) were chosen as models to investigate the adsorption properties of Co-MOF. More details of adsorption experiments are given in the supporting information. As illustrated in Fig. 3, the adsorption capacities of the Co-MOF for $\mathrm{MB}, \mathrm{RhB}, \mathrm{CR}$, and $\mathrm{GV}$ at room temperature are 44.93, 3.92, 81.4, and $10.10 \mathrm{mg} \mathrm{g}^{-1}$ at $360 \mathrm{~min}$, respectively. However, Co-MOF exhibited an adsorption capacity of $235.64 \mathrm{mg} \mathrm{g}^{-1}$ for MO in only $10 \mathrm{~min}$, thus demonstrating it is highly selective toward $\mathrm{MO}$ and offers rapid and efficient capture of this dye (Fig. 3). According to the literatures, the mechanism of dye adsorption is host-guest interactions with electrostatic interaction, hydrogen bonding or $\pi-\pi$ stacking. ${ }^{45}$

However, the existing dye adsorption techniques are expensive due to their poor recyclabilities. It is of great significance to find an inexpensive adsorbent with reversible adsorption capabilities. On this basis, we have synthesized C@Co using the Co-MOF as a combined catalyst and precursor via the CVD method. At time intervals of $360 \mathrm{~min}$, the dye concentration was measured via UV-Vis spectroscopy (Figs. $4 \mathrm{a}-4 \mathrm{e}$ ). The dye adsorption capacities of the C@Co adsorbent for MB, RhB, MO, CR, and GV at room temperature are $65.35,50.88,773.48,495.66$, and $43.62 \mathrm{mg} \mathrm{g}^{-1}$, respectively (Fig. 4f). In comparison with other adsorbents, the adsorption capacities of the C@Co for MB, RhB and GV are not the highest. ${ }^{46} \mathrm{However}$ we note that the adsorption capacities of our C@Co adsorbent for CR and MO are much higher than those of other dyes. The presence of - $\mathrm{OH}$ and - $\mathrm{COOH}$ in the $\mathrm{C} @ \mathrm{Co}$ and amino groups of $\mathrm{MO}$ and $\mathrm{CR}$ might promote the formation of numerous hydrogen bonding interactions. ${ }^{47}$ Moreover, the favorable adsorption of $\mathrm{MO}$ and $\mathrm{CR}$ could be attributed to the electrostatic attraction between the negatively charged aqueous solution of MO and CR and the positively charged surfaces of the C@Co. ${ }^{48}$ At the same time, $\pi-\pi$ interaction between the surface of the carbon-based material and the aromatic compounds of dyes was considered to be the main contributor of the adsorption mechanism. Hence, these features demonstrate that the title C@Co can be a highly effective sorbent for the selective removal of dye species from water. Interestingly, the magnetic separation of C@Co was further tested with a magnet (Fig. S1). C@Co quickly to external magnetic fields and can be absolutely isolated from an aqueous solution by a magnet. This feature facilitates the recycling of this adsorbent.

\subsection{Effect of contact time on adsorption performance.}

The effect of contact time on the adsorption of MO and CR by C@Co is displayed in Fig. 4f. The initial concentration of $\mathrm{MO}$ and $\mathrm{CR}$ are 40 and $80 \mathrm{mg} \mathrm{L}^{-1}$, respectively, at room temperature. It can be seen that 
the adsorption capacities of C@Co for MO and CR increase rapidly as the contact time is increased from 0 to $180 \mathrm{~min}$, due to the large number of vacant adsorption sites and the large surface area of this adsorbent. The adsorption rate began to slow down gradually during $180 \mathrm{~min}$, mainly due to the lower $\mathrm{MO}$ and $\mathrm{CR}$ concentration, resulting in a weaker adsorption driving force while the number of surface active adsorption sites also decreased. After $360 \mathrm{~min}$, the adsorption capacity reached equilibrium, and the equilibrium adsorption capacities were 733.33 and $495.66 \mathrm{mg} \mathrm{g}^{-1}$ for $\mathrm{MO}$ and $\mathrm{CR}$, respectively.

\subsection{Effect of temperature on adsorption performance.}

Temperature is one of the significant factors influencing the adsorption process. In particular, it affects the physical and chemical properties of the adsorbent and the diffusion rate of the adsorbed molecules and determines the adsorption capacity. ${ }^{49}$ In this experiment, the effect of temperature on the adsorption of MO and CR by C@Co was studied at 298, 303, 313, and 323 K, respectively. It can be seen that the initial concentration of $\mathrm{MO}$ and $\mathrm{CR}$ is 40 and $80 \mathrm{mg} \mathrm{L}^{-1}$ and the adsorption capacity reaches 733.33 and $495.66 \mathrm{mg} \mathrm{g}^{-1}$ (Figs. 5 and S2). These results show that the adsorption capacity increases at higher temperatures. It may be caused by the electrostatic interactions between C@Co and dye molecules at higher temperatures. The results suggest that the adsorption of MO and CR on C@Co is an endothermic process. ${ }^{50}$

\subsection{Effect of concentration on adsorption performance.}

The initial concentration of the solution is another crucial factor affecting the adsorption process. It affects adsorption by changing the adsorbent and the protonation of the adsorbent's surface functional groups. The effect of the concentration of the solution on the MO and CR adsorption capacity of C@Co is shown in Figs. 6 and S3, and it can be seen that the adsorption capacity increases at higher dye concentrations. As the concentration of the dyes is increases, eventually the adsorption sites on C@Co become occupied, so that a certain adsorption capacity is eventually reached.

\subsection{Adsorption isotherms.}

Many mathematical models have been used to describe the relationship between the adsorption capacity of adsorbents and the residual concentration in solution. The choice of isotherm model depends on the properties and types of adsorbents and adsorbates under investigation. ${ }^{51}$ In this work, the Langmuir and Friedrich models were used to further investigate the adsorption performance of C@Co and the reaction between adsorbents and adsorbates. The Langmuir model assumes that happens uniformly on the surface to form a monolayer of the adsorbed complex on the surface of $\mathrm{C} @ \mathrm{Co}$, and all adsorption sites are identical and independent of each other. By linear fitting the scatter plot of the above equation, a linear curve can be obtained (Figs. S4 and S5). According to the slope and intercept of the curve in the figures, the values of $q_{\max }$ and $k_{L}$ can be obtained (Tables 1 and S3). The maximum of MO theoretical

adsorption capacities at 298, 303, 313, and $323 \mathrm{~K}$ are $772.75,772.95,773.09$ and $773.33 \mathrm{mg} \mathrm{g}^{-1}$ respectively, while the maximum theoretical adsorption capacities of CR are 476.86, 483.20, 491.15 and 
$495.66 \mathrm{mg} \mathrm{g}^{-1}$, respectively. The decision coefficient of the Langmuir equation $\left(R^{2}\right)$ is $>0.99$. These results show that the adsorption of MO and CR onto C@Co are in accordance with the Langmuir model, thus suggesting that they are adsorbed in the form of a monolayer. As shown in Table 1, all $R_{L}$ values are between 0 and 1, indicating that $\mathrm{C} @$ Co has a higher adsorption capacity for $\mathrm{MO}$ and $\mathrm{CR}$ than for the other dyes. ${ }^{52}$

Table 1

The adsorption isotherm constants of the Langmuir and Freundlich models for the adsorption of MO onto C@Co.

\begin{tabular}{|c|c|c|c|c|c|c|c|}
\hline \multirow{2}{*}{$\begin{array}{l}\text { Temperature } \\
\text { (K) }\end{array}$} & \multicolumn{4}{|c|}{ Langmuir model } & \multicolumn{3}{|c|}{ Freundlich model } \\
\hline & $\begin{array}{l}q_{\max }\left(\mathrm{mg} \mathrm{g}^{-}\right. \\
\left.{ }^{1}\right)\end{array}$ & $\begin{array}{l}k_{L} \\
\left(\mathrm{~L} \mathrm{mg}^{-1}\right)\end{array}$ & $R^{2}$ & $R_{L}$ & $\begin{array}{l}k_{F} \\
(\mathrm{~L} \mathrm{mg-} \\
\left.{ }^{1}\right)\end{array}$ & $1 / n$ & $R^{2}$ \\
\hline 298 & 772.875 & $\begin{array}{l}2.68 \times 10^{-} \\
4\end{array}$ & 0.9687 & $\begin{array}{l}0.0362- \\
0.0447\end{array}$ & 6.9566 & 0.6432 & 0.8197 \\
\hline 303 & 772.951 & $\begin{array}{l}2.63 \times 10^{-} \\
4\end{array}$ & 0.9698 & $\begin{array}{l}0.0368- \\
0.0455\end{array}$ & 6.9141 & 0.6178 & 0.8003 \\
\hline 313 & 773.092 & $\begin{array}{l}2.56 \times 10^{-} \\
4\end{array}$ & 0.9721 & $\begin{array}{l}0.0378- \\
0.0472\end{array}$ & 6.9177 & 0.6127 & 0.8026 \\
\hline 323 & 773.339 & $\begin{array}{l}2.49 \times 10^{-} \\
4\end{array}$ & 0.9734 & $\begin{array}{l}0.0388- \\
0.0489\end{array}$ & 6.9208 & 0.6078 & 0.8145 \\
\hline
\end{tabular}

As shown in Figs. $\mathrm{S} 6$ and $\mathrm{S7}$, the values of $K_{F}$ and $1 / n$ can be respectively determined from the slope and intercept of a Freundlich plot. The decision coefficient of Freundlich equation is $R^{2}>0.99$, thus suggesting that the adsorption of MO and CR by C@Co is in accordance with the Freundlich model (Table 1). The Langmuir and the Freundlich isotherm charts and parameters indicate that the adsorption conformed to the two models. According to the calculations performed via the Langmuir equation, the biggest adsorption capacity of C@Co reaches 773.33 and $495.66 \mathrm{mg} \mathrm{g}^{-1}$ for MO and CR, respectively, which indicates that C@Co is an excellent adsorbent calculated by the Freundlich equation, $1 / n$ is less than 1 which indicates that it is conducive to the adsorption reaction. ${ }^{53}$

\subsection{Adsorption kinetics.}

Several kinetic models, such as the quasi-first-order kinetic model, the quasi-second-order kinetic model and the internal particle diffusion model, are often used to evaluate adsorption data. ${ }^{54}$ As shown in Table 2, the values of $k_{1}$ and $q_{e}$ can be determined from the intercept and slope of the plots shown in Fig. 7. Although the coefficient of determination $\left(R^{2}\right)$ is close to 1 , there is a significant difference between the calculated $q_{e}\left(2.97\right.$ and $\left.0.97 \mathrm{mg} \mathrm{g}^{-1}\right)$ and the experimental $q_{e}$ values (773.33 and $\left.495.66 \mathrm{mg} \mathrm{g}^{-1}\right)$, 
indicating that the quasi-first-order kinetic model is unsuitable for this experiment. A polt of $t / q_{t}$ versus $t$ is shown in Figs. $7 \mathrm{c}$ and $\mathrm{d}$, and the values of $k_{2}$ and $q_{e}$ are acquired from the slope and intercept of this plot. The determination coefficients are 0.9723 and 0.9641 for $\mathrm{MO}$ and $\mathrm{CR}$, respectively, and the calculated $q_{e}$ values (773.33 and $495.66 \mathrm{mg} \mathrm{g}^{-1}$ ) are very close to the experimental $q_{e}$ values (773.33 and $495.66 \mathrm{mg}$ $\left.\mathrm{g}^{-1}\right)$, thus indicating that the quasi-second-order kinetic model can accurately describe the kinetics of MO and CR adsorption onto C@Co. Therefore, the adsorption rate is controlled by chemical adsorption, and the adsorbent and the adsorbed material exchange electrons through shared electrons or covalent forces. $^{54}$

Table 2

The parameters of the pseudo-first-order, pseudo-second-order, and intra-particle diffusion models.

\begin{tabular}{|c|c|c|c|}
\hline Kinetic model & Parameters & $\begin{array}{l}\text { MO } \\
\left(40 \mathrm{mg} \mathrm{L}^{-1}\right)\end{array}$ & $\begin{array}{l}\text { CR } \\
\left(80 \mathrm{mg} \mathrm{L}^{-1}\right)\end{array}$ \\
\hline \multirow[t]{3}{*}{ Pseudo-first-order model } & $k_{1}\left(\min ^{-1}\right)$ & -0.00427 & -0.00625 \\
\hline & $q_{e}\left(\mathrm{mg} \mathrm{g}^{-1}\right)$ & 2.97978 & 2.39548 \\
\hline & $R^{2}$ & 0.98130 & 0.96398 \\
\hline \multirow[t]{3}{*}{ Pseudo-second-order model } & $k_{2}\left(\mathrm{~g} \mathrm{mg}^{-1} \min ^{-1}\right)$ & 0.00169 & 0.00196 \\
\hline & $q_{e}\left(\mathrm{mg} \mathrm{g}^{-1}\right)$ & 0.05196 & 0.08215 \\
\hline & $R^{2}$ & 0.97230 & 0.96416 \\
\hline \multirow[t]{3}{*}{ Intra-particle diffusion model } & $k_{i d}\left(\mathrm{mg} \mathrm{g}^{-1} \min ^{-1 / 2}\right)$ & -239.70 & -258.33 \\
\hline & $C\left(\mathrm{mg} \mathrm{g}^{-1}\right)$ & 32.8970 & 32.9037 \\
\hline & $R^{2}$ & 0.98510 & 0.98923 \\
\hline
\end{tabular}

The internal particle diffusion model is usually used to determine the rate control steps in porous structures. ${ }^{54}$ As shown in Fig. S8 and described in Table 2. The determination coefficients $R^{2}$ of the internal particle diffusion model are 0.98510 and 0.98923 , which are higher than those of the quasisecond order equation. The curve is nonlinear and the intercept is unequal to zero and does not pass through the origin, which indicates that the internal particle diffusion is the only rate determining step, and the adsorption of $\mathrm{MO}$ and $\mathrm{CR}$ on C@CO are simple process. ${ }^{55}$

\subsection{Adsorption thermodynamics.}


Due to the impact of temperature on the adsorption of $\mathrm{MO}$ and $\mathrm{CR}$ by $\mathrm{C} @ \mathrm{Co}$, the thermodynamic parameters of C@Co, MO, and CR were studied at different temperatures. The values of $\Delta H$ and $\Delta S$ are calulated according to the slope and intercept of the corresponding van't Hoff plot (Fig. S9). ${ }^{56} \Delta G$ is negative, suggesting that the adsorption process is spontaneous (Tables 3 and S4). Additionally, as the temperature is ranged from 298 to $323 \mathrm{~K}$, the $\Delta G$ of MO cut down about $2.00 \mathrm{~kJ} \mathrm{~mol}^{-1}$, while the $\Delta G$ of $\mathrm{CR}$ reduces from -5.47 to $-5.99 \mathrm{KJ} \mathrm{mol}^{-1}$, suggesting that a higher temperature is more beneficial for adsorption. Otherwise, the negative value of $\Delta H\left(3.87\right.$ and $\left.0.79 \mathrm{~kJ} \mathrm{~mol}^{-1}\right)$ indicated that the interactions between $\mathrm{C} @ \mathrm{Co}$ and $\mathrm{MO}$ or $\mathrm{CR}$ are endothermic processes. The positive $\Delta S$ suggests that the randomness of the system increases as the MO and CR are adsorbed onto C@Co. ${ }^{56}$

Table 3

Thermodynamic arguments at various temperatures.

\begin{tabular}{|llll|}
\hline $\boldsymbol{T}(\mathrm{K})$ & $\boldsymbol{\Delta} \boldsymbol{G ( \mathrm { kJ } \mathrm { mol } ^ { - 1 } )}$ & $\boldsymbol{\Delta} \boldsymbol{H}\left(\mathrm{kJ} \mathrm{mol}^{-1}\right)$ & $\boldsymbol{\Delta}\left(\mathrm{kJ} \mathrm{mol}^{-1} \mathrm{~K}^{-1}\right)$ \\
\hline 298 & -19.97 & 3.87 & 0.08 \\
303 & -20.37 & & \\
313 & -21.17 & & \\
\hline 323 & -21.97 & & \\
\hline
\end{tabular}

\subsection{Comparison of adsorption efficiencies with other adsorbents.}

Table 4 shows the adsorption efficiencies of the C@Co nanocomposite and those of other adsorbents reported in the literatures. ${ }^{57-72}$ The results demonstrate that the C@Co shows a higher adsorption capacity than the other MOF-based and carbon-based adsorbents. In spite of some adsorbents may have demonstrated competitive adsorption efficiency, their removal conditions such as adsorbent amount are quite high. The enhanced dye adsorption performance of the magnetic C@Co material indicates that it can afford a selective and high-efficient adsorbent for the remove of wastewater. Sum up, the magnetic properties of the C@Co nanocomposite is an excellent adsorbent for wastewater treatment in demanding conditions. 
Table 4

Adsorption capacities of different adsorbents for MO.

\begin{tabular}{|c|c|c|}
\hline Absorbent & Adsorption capacity $(\mathrm{mg} / \mathrm{g})$ & Ref. \\
\hline Carbon nanotubes & 64.70 & 57 \\
\hline$\lambda-\mathrm{Fe}_{2} \mathrm{O}_{3} / \mathrm{MWCNTs} /$ chitosan & 66.10 & 58 \\
\hline $\mathrm{QPEI} / \mathrm{SiO}_{2}$ & 105.00 & 59 \\
\hline Ni-containing ordered mesoporous carbon & 107.10 & 60 \\
\hline Chitin/alginate magnetic nano-gel beads (MCAs) & 107.50 & 61 \\
\hline MIL-101 (Fe) & 117.70 & 62 \\
\hline Acid modified carbon coated monolith & 132.70 & 63 \\
\hline MIL-100(Fe) & 145.70 & 64 \\
\hline Alkali-activated multiwalled carbon nanotubes & 149.00 & 65 \\
\hline carbon nanotubes (CNTs-A) & 149.00 & 65 \\
\hline GO/MIL-101 (Fe) & 186.20 & 63 \\
\hline Calcined layered double hydroxides & 200.00 & 66 \\
\hline Mesoporous carbon CMK-3 & 294.10 & 67 \\
\hline $\mathrm{Cu} @ \mathrm{Cu}_{2} \mathrm{O}$ & 344.80 & 68 \\
\hline Mesoporous magnetic Co-NPs/carbon nanocomposites & 380.00 & 69 \\
\hline Mesoporous $\mathrm{Y}-\mathrm{Fe}_{2} \mathrm{O}_{3} /$ calcined $\mathrm{SiO}_{2}$ nanocomposites & 476.00 & 70 \\
\hline Mn@Si/Al & 571.00 & 71 \\
\hline c@Co & 733.33 & This work \\
\hline
\end{tabular}

\section{Conclusions}

In summary, a magnetic C@Co material was successfully synthesized with the use of Co-MOF as a catalyst precursor via the CVD method. The as-grown C@Co shown a highly selective adsorption capacity toward anionic dyes, and the adsorption capacities were $773.33 \mathrm{mg} \mathrm{g}^{-1}$ and $495.66 \mathrm{mg} \mathrm{g}^{-1}$ for $\mathrm{MO}$ and for $\mathrm{CR}$, respectively. Moreover, a viable adsorption mechanism has been proposed, which suggests that non-covalent interaction (hydrogen bonding and $\pi-\pi$ stacking interaction) is a key role in the adsorption process. The internal particle diffusion is the only rate determining step which the adsorptions of $\mathrm{MO}$ and CR on C@CO are simple processes. Thermodynamic studies suggest that the adsorption processes are 
spontaneous and exothermic. The resulting C@Co was discovered to be an efficient adsorbent material for the removal of anionic dyes from aqueous solutions. This research may open up new routes toward.

\section{Declarations}

\section{CRediT authorship contribution statement}

Yu Liu and Yan Wang-Crystal synthesis, writing-original draft preparation. Xiao-Sa Zhang and Ai-Ai Yang-Formal analysis, investigation; Hong-Zhu Liu and Zhong-Gang Wang-Software; Wen-Ze Li and Jian Luan-Writing-review \& editing.

\section{Declaration of Competing Interest}

The authors declare that they have no known competing financial interests or personal relationships that could have appeared to influence the work reported in this paper.

\section{Acknowledgement}

This work was financially supported by the Liaoning Provincial Department of Education Fund (LQ2019004 and LZ2019005).

\section{References}

1. C.J. Vörösmarty, P.B. McIntyre, M.O. Gessner, D. Dudgeon, A. Prusevich, P. Green, S. Glidden, S.E. Bunn, C.A. Sullivan, C.R. Liermann, P.M. Davies. Global threats to human water security and river biodiversity. Nature 467, 555-561 (2010)

2. S. Wang, B. Zhang, C. Shan, X. Yan, H. Chen, B. Pan. Occurrence and transformation of phosphonates in textile dyeing wastewater along full-scale combined treatment processes. Water Res 184, 116173 (2020)

3. C. Ding, M. Yi, B. Liu, C. Han, X. Yu, Y. Wang, Forward osmosis-extraction hybrid process for resource recovery from dye wastewater. J Membrane Sci 612, 118376 (2020)

4. A. Prasannan, J. Udomsin, H. Tsai, M. Sivakumar, C. Hu, C. Wang, W. Hung, J. Lai. Special wettable underwater superoleophobic material for effective simultaneous removal of high viscous insoluble oils and soluble dyes from wastewater. J Membrane Sci 603, 118026 (2020)

5. L. Yang, Y. Zhan, R. Yu, J. Lan, J. Shang, B. Dou, H. Liu, R. Zou, S. Lin. Facile and Scalable Fabrication of Antibacterial $\mathrm{CO}_{2}$-Responsive Cotton for Ultrafast and Controllable Removal of Anionic Dyes. ACS Appl Mater Inter 13, 2694-2709 (2021)

6. A. Malik, M. Nath, Synthesis of Ag/ZIF-7 by immobilization of Ag nanoparticles onto ZIF-7 microcrystals: A heterogeneous catalyst for the reduction of nitroaromatic compounds and organic dyes. J Environment Chem Eng 8, 104547 (2020) 
7. Y. Gao, S. Yan, Y. He, Y. Fan, L. Zhang, J. Ma, R. Hou, L. Chen, J. Chen. A photo-Fenton self-cleaning membrane based on $\mathrm{NH}_{2}-\mathrm{MIL}-88 \mathrm{~B}(\mathrm{Fe})$ and graphene oxide to improve dye removal performance. $\mathrm{J}$ Membrane Sci 626, 119192 (2021)

8. Y. Yang, Z. Xiong, Z. Wang, Y. Liu, Z. He, A. Cao, L. Zhou, L. Zhu, S. Zhao, Super-adsorptive and photoregenerable carbon nanotube based membrane for highly efficient water purification. J Membrane Sci 621, 119000 (2021)

9. S. Zhou, X. Feng, J. Zhu, Q. Song, G. Yang, Y. Zhang, B. Van der Bruggen. Self-cleaning loose nanofiltration membranes enabled by photocatalytic Cu-triazolate MOFs for dye/salt separation. $J$ Membrane Sci 623, 119058 (2021)

10. X. Zhang, Z. Li, S. Lin, P. Théato, Fibrous Materials Based on Polymeric Salicyl Active Esters as Efficient Adsorbents for Selective Removal of Anionic Dye. ACS Appl Mater Inter 12, 21100-21113 (2020)

11. H. Liang, R. Sun, B. Song, Q. Sun, P. Peng, D. She, Preparation of nitrogen-doped porous carbon material by a hydrothermal-activation two-step method and its high-efficiency adsorption of $\operatorname{Cr}(\mathrm{VI})$. J. Hazard. Mater. 387, 121987 (2020)

12. E. Santoso, R. Ediati, Y. Kusumawati, H. Bahruji, D.O. Sulistiono, D. Prasetyoko, Review on recent advances of carbon based adsorbent for methylene blue removal from waste water. Mater Today Chem 16, 100233 (2020)

13. X. Wu, D. Huang, Y. Wu, J. Zhao, X. Liu, W. Dong, S. Li, D. Li, J. Li. In Situ Synthesis of Nano CuSEmbedded MOF hierarchical structures and application in dye adsorption and hydrogen evolution reaction. ACS Appl Energy Mater 2, 5698-5706 (2019)

14. W. Shao, C. He, M. Zhou, C. Yang, Y. Gao, S. Li, L. Ma, L. Qiu, C. Cheng, C. Zhao, Core-shell-structured MOF-derived 2D hierarchical nanocatalysts with enhanced Fenton-like activities. J Mater Chem A 8, 3168-3179 (2020)

15. C. Yu, J. Chen, Y. Zhang, W. Song, X. Li, F. Chen, Y. Zhang, D. Liu, L. Liu, Highly efficient and selective removal of anionic dyes from aqueous solution by using a protonated metal-organic framework. $J$ Alloy Compound 853, 157383 (2021)

16. T. Selkälä, T. Suopajärvi, J.A. Sirviö, T. Luukkonen, P. Kinnunen, A.L.C.B. de Carvalho, H. Liimatainen. Surface modification of cured inorganic foams with cationic cellulose nanocrystals and their use as reactive filter media for anionic dye removal. ACS Appl Mater Inter 12, 27745-27757 (2020)

17. L. Yang, Y. Zhan, R. Yu, J. Lan, J. Shang, B. Dou, H. Liu, R. Zou, S. Lin. Facile and scalable fabrication of antibacterial $\mathrm{CO}_{2}$-responsive cotton for ultrafast and controllable removal of anionic Dyes. ACS Appl Mater Inter 13, 2694-2709 (2021)

18. S. Das, P. Chakraborty, R. Ghosh, S. Paul, S. Mondal, A. Panja, A.K. Nandi, Folic acid-polyaniline hybrid hydrogel for adsorption/reduction of chromium $(\mathrm{VI})$ and selective adsorption of anionic dye from water. ACS Sus Chem Eng 10, 9325-9337 (2017)

19. Z. Li, K. Zou, X. Zhang, T. Han, Y. Yang, Hierarchically Flower-like N-Doped Porous Carbon Materials Derived from an Explosive 3-Fold Interpenetrating Diamondoid Copper Metal-Organic Framework for 
a Supercapacitor. Inorg. Chem. 55, 6552-6562 (2016)

20. X. Wu, J. Zhao, Y. Wu, W. Dong, D. Li, J. Li, Q. Zhang, Ultrafine Pt Nanoparticles and Amorphous Nickel Supported on 3D Mesoporous Carbon Derived from Cu-Metal-Organic Framework for Efficient Methanol Oxidation and Nitrophenol Reduction. ACS Appl Mater Inter 10, 12740-12749 (2018)

21. K. Nath, C.K. Karan, K. Biradha, Metal-organic frameworks and metal-organic framework-derived Ndoped porous carbon materials as heterogeneous catalysts: Chemical fixation of carbon dioxide under mild conditions and electrochemical hydrogen evolution. Cryst. Growth Des. 19, 6672-6681 (2019)

22. B. Volosskiy, H. Fei, Z. Zhao, S. Lee, M. Li, Z. Lin, B. Papandrea, C. Wang, Y. Huang, X. Duan. Tuning the catalytic activity of a metal-organic framework derived copper and nitrogen Co-doped carbon composite for oygen reduction reaction. ACS Appl Mater Inter 8, 26769-26774 (2016)

23. R. Rajak, M. Saraf, A. Mohammad, S.M. Mobin, Design and construction of a ferrocene based inclined polycatenated Co-MOF for supercapacitor and dye adsorption applications. J. Mater. Chem. A 5, 17998-18011 (2017)

24. Y. Zhang, H. Zhang, X. Wu, Z. Deng, E. Zhou, Z. Yu. Nanolayered Cobalt@Carbon Hybrids derived from metal-organic frameworks for microwave absorption. ACS Appl Nano Mater 2, 2325-2335 (2019)

25. M. Hasanzadeh, A. Simchi, H. Shahriyari, Far, Nanoporous composites of activated carbon-metal organic frameworks for organic dye adsorption: Synthesis, adsorption mechanism and kinetics studies. J Ind Eng Chem 81, 405-414 (2020)

26. D. Wang, F. Zeng, X. Hu, C. Li, Z. Su, Synthesis of a magnetic 2D Co@NC-600 material by designing a MOF precursor for efficient catalytic reduction of water pollutants. Inorg. Chem. 59, 12672-12680 (2020)

27. K. Zou, Y. Liu, Y. Jiang, C. Yu, M. Yue, Z. Li, Benzoate acid-dependent lattice dimension of Co-MOFs and MOF-derived CoS ${ }_{2} @ C N T s$ with tunable Pore diameters for supercapacitors. Inorg. Chem. 56, 6184-6196 (2017)

28. Y. Zhang, H. Zhang, X. Wu, Z. Deng, E. Zhou, Z. Yu. Nanolayered Cobalt@carbon hybrids derived from metal-organic frameworks for microwave absorption. ACS Appl Nano Mater 2, 2325-2335 (2019)

29. S.Y. Mendiola-Alvarez, P.G. Turnes, J. Guzman-Mar, A. Hernandez-Ramirez, L. Hinojosa-Reyes, C.C. Palomino, Magnetic porous carbons derived from cobalt(ii)-based metal-organic frameworks for the solid-phase extraction of sulfonamides. Dalton Trans. 49, 8959-8966 (2020)

30. J. Liu, S. Ma, L. Zang, Preparation and characterization of ammonium-functionalized silica nanoparticle as a new adsorbent to remove methyl orange from aqueous solution. Appl Surf Sci $\mathbf{2 6 5}$, 393-398 (2013)

31. M.A. Ahsan, O. Fernandez-Delgado, E. Deemer, H. Wang, A.A. El-Gendy, M.L. Curry, J.C. Noveron, Carbonization of Co-BDC MOF results in magnetic C@Co nanoparticles that catalyze the reduction of methyl orange and 4-nitrophenol in water. J Mol liquid 290, 111059 (2019) 
32. M.A. Nazir, N.A. Khan, C. Cheng, S.S.A. Shah, T. Najam, M. Arshad, A. Sharif, S. Akhtar, A.U. Rehman, Surface induced growth of ZIF-67 at Co-layered double hydroxide: Removal of methylene blue and methyl orange from water. Appl Clay Sci 190, 105564 (2020)

33. M. Trukawka, K. Cendrowski, M. Peruzynska, A. Augustyniak, P. Nawrotek, M. Drozdzik, E. Mijowska. Carbonized metal-organic frameworks with trapped cobalt nanoparticles as biocompatible and efficient azo-dye adsorbent. Environ Sci Eur 31, 56 (2019)

34. L. Li, S. Zhang, X. Zhang, G. Zheng, Polyamide thin film composite membranes prepared from isomeric biphenyl tetraacyl chloride and m-phenylenediamine. J Membrane Sci 315, 20-27 (2008)

35. Z.R. Pan, J. Xu, X.Q. Yao, Y.Z. Li, Z.J. Guo, H.G. Zheng, Syntheses, structures, magnetic and photoluminescence properties of metal-organic frameworks based on aromatic polycarboxylate acids. CrystEngComm 13, 1617-1624 (2011)

36. J. Long, K. Shen, Y. Li, Bifunctional N-doped Co@C catalysts for base-free transfer hydrogenations of nitriles: Controllable selectivity to primary amines vs imines. ACS Catal 7, 275-284 (2017)

37. K. Zou, Y. Liu, Y. Jiang, C. Yu, M. Yue, Z. Li, Benzoate acid-dependent lattice dimension of Co-MOFs and MOF-derived $\mathrm{CoS}_{2} @ C N T s$ with tunable pore diameters for supercapacitors. Inorg. Chem. 56, 6184-6196 (2017)

38. S. Gutiérrez-Tarriño, J.L. Olloqui-Sariego, J.J. Calvente, G.M. Espallargas, F. Rey, A. Corma, P. OñaBurgos. Cobalt metal-organic framework based on layered double nanosheets for enhanced electrocatalytic water oxidation in neutral media. J. Am. Chem. Soc. 142, 19198-19208 (2020)

39. P.L. Feng, J.J. Perry, S. Nikodemski, B.W. Jacobs, S.T. Meek, M.D. Allendorf, Assessing the purity of metal - organic frameworks using photoluminescence: MOF-5, ZnO quantum dots, and framework decomposition. J. Am. Chem. Soc. 132, 15487-15489 (2010)

40. R. Rajak, M. Saraf, A. Mohammad, S.M. Mobin, Design and construction of a ferrocene based inclined polycatenated Co-MOF for supercapacitor and dye adsorption applications. J Mater Chem A 5, 17998-18011 (2017)

41. D. Wang, J. Zhang, G. Li, J. Yuan, J. Li, Q. Huo, Y. Liu, Mesoporous hexanuclear copper cluster-based metal-organic framework with highly selective adsorption of gas and organic dye molecules. ACS Appl Mater Inter 10, 31233-31239 (2018)

42. X. Yang, Y. Yan, W. Wang, Z. Hao, W. Zhang, W. Huang, Y. Wang, A 2-fold interpenetrated nitrogen-rich metal-organic framework: dye adsorption and $\mathrm{CO}_{2}$ capture and conversion. Inorg. Chem. 60, 31563164 (2021)

43. W. Fan, X. Wang, B. Xu, Y. Wang, D. Liu, M. Zhang, Y. Shang, F. Dai, L. Zhang, D. Sun, Aminofunctionalized MOFs with high physicochemical stability for efficient gas storage/separation, dye adsorption and catalytic performance. J Mater Chem A 6, 24486-24495 (2018)

44. S. Zhan, D. Zhu, G. Ren, Z. Shen, M. Qiu, S. Yang, H. Yu, Y. Li, Coaxial-electrospun magnetic coreshell Fe@TiSi nanofibers for the rapid purification of typical dye wastewater. ACS Appl Mater Inter 6, $16841-16850$ (2014) 
45. J. Zhao, J. Luan, H.X. Yu, G.C. Liu, H.Y. Lin, X.L. Wang, B.K. Chen, Five naphthalene-amide-bridged $\mathrm{Ni}(\mathrm{II})$ complexes: electrochemistry, bifunctional fluorescence responses, removal of contaminants and optimization by CVD. CrystEngComm 22, 1330-1339 (2020)

46. S.K. Konavarapu, A. Goswami, A.G. Kumar, S. Banerjee, K. Biradha, MOFs containing a linear bispyridyl-tris-amide and angular carboxylates: exploration of proton conductivity, water vapor and dye sorptions. Inorg Chem Front 6, 184-191 (2019)

47. L.J. Han, F.Y. Ge, G.H. Sun, X.J. Gao, H.G. Zheng, Effective adsorption of Congo red by a MOF-based magnetic material. Dalton Trans. 48, 4650-4656 (2019)

48. W.A. El-Mehalmey, Y. Safwat, M. Bassyouni, M.H. Alkordi, Strong interplay between polymer surface charge and MOF cage chemistry in mixed-matrix membrane for water treatment applications. ACS Appl Mater Inter 12, 27625-27631 (2020)

49. S.C.C. van der Lubbe, F. Zaccaria, X. Sun, C. Fonseca Guerra. Secondary Electrostatic Interaction Model Revised: Prediction Comes Mainly from Measuring Charge Accumulation in Hydrogen-Bonded Monomers. J. Am. Chem. Soc. 141, 4878-4885 (2019)

50. X. Zhang, Z. Li, S. Lin, P. Théato, Fibrous materials based on polymeric salicyl active esters as efficient adsorbents for selective removal of anionic dye. ACS Appl Mater Inter 12, 21100-21113 (2020)

51. F. Gritti, G. Guiochon, Analytical solution of the ideal model of chromatography for a Bi-Langmuir adsorption isotherm. Anal. Chem. 85, 8552-8558 (2013)

52. S. Nufer, M.J. Large, A.A.K. King, S.P. Ogilvie, A. Brunton, A.B. Dalton, Edge-selective gas detection using Langmuir films of graphene platelets. ACS Appl Mater Inter 18, 21740-21745 (2018)

53. I. Abe, K. Hayashi, T. Hirashima, M. Kitagawa, Relationship between the Freundlich adsorption constants $\mathrm{K}$ and 1/N hydrophobic adsorption. J. Am. Chem. Soc. 104, 6452-6453 (1982)

54. A.J.S. Ribeiro, K. Zaleta-Rivera, E.A. Ashley, B.L. Pruitt, Stable, Covalent attachment of laminin to microposts improves the contractility of mouse neonatal cardiomyocytes. ACS Appl Mater Inter 6, $15516-15526$ (2014)

55. X. Ni, G. Dong, L. Li, Q. Yang, Z. Wu, Kinetic study of electron transport behaviors used for ion sensing technology in air/ EGR diluted methane flames. Fuel 288, 119825 (2021)

56. J.C. Moreno-López, A. Pérez, S. Paz, L. Gottardi, J. Solianyk, L. Li, A.K.H. Monjas, D.J. Hirsch, M. Mowbray, Stöhr, Unveiling adatoms in on-surface reactions: Combining scanning probe microscopy with van't Hoff plots. J. Phys. Chem. C 125, 9847-9854 (2021)

57. Y. Yao, H. Bing, X. Feifei, C. Xiaofeng, Equilibrium and kinetic studies of methyl orange adsorption on multiwalled carbon nanotubes. Chem. Eng. J. 170, 82-89 (2011)

58. H.Y. Zhu, R. Jiang, L. Xiao, G.M. Zeng, Preparation, characterization, adsorption kinetics and thermodynamics of novel magnetic chitosan enwrapping nanosized $\mathrm{y}-\mathrm{Fe}_{2} \mathrm{O}_{3}$ and multi-walled carbon nanotubes with enhanced adsorption properties for methyl orange. Bioresour. Technol. 101, 5063-5069 (2010) 
59. J. Liu, S. Ma, L. Zang, Preparation and characterization of ammonium-functionalized silica nanoparticle as a new adsorbent to remove methyl orange from aqueous solution. Appl Surf Sci $\mathbf{2 6 5}$, 393-398 (2013)

60. Y. Tian, X. Wang, Y. Pan, Simple synthesis of Ni-containing ordered mesoporous carbons and their adsorption/desorption of methylene orange. J Hazard Mater, 213-214 (2012) 361-368

61. G. Li, Y. Du, Y. Tao, H. Deng, X. Luo, J. Yang, Iron(II) cross-linked chitin-based gel beads: Preparation, magnetic property and adsorption of methyl orange. Carbohydr. Polym. 82, 706-713 (2010)

62. Z. Liu, W. He, Q. Zhang, H. Shapour, M.F. Bakhtari, Preparation of a GO/MIL-101(Fe) composite for the removal of methyl orange from aqueous solution. ACS Omega 6, 4597-4608 (2021)

63. W. Cheah, S. Hosseini, M.A. Khan, T.G. Chuah, T.S.Y. Choong, Acid modified carbon coated monolith for methyl orange adsorption. Chem Eng J, 215-216 (2013) 747-754

64. K. Guesh, C.A.D. Caiuby, Á Mayoral, M. Díaz-García, I. Díaz, M. Sanchez-Sanchez, Sustainable preparation of MIL-100(Fe) and its photocatalytic behavior in the degradation of methyl orange in water. Cryst. Growth Des. 17, 1806-1813 (2017)

65. J. Ma, F. Yu, L. Zhou, L. Jin, M. Yang, J. Luan, Y. Tang, H. Fan, Z. Yuan, J. Chen, Enhanced adsorptive removal of methyl orange and methylene blue from aqueous solution by alkali-activated multiwalled carbon nanotubes. ACS Appl Mater Inter 4, 5749-5760 (2012)

66. Z. Ni, S. Xia, L. Wang, F. Xing, G. Pan, Treatment of methyl orange by calcined layered double hydroxides in aqueous solution: Adsorption property and kinetic studies. J. Colloid Interface Sci. 316, 284-291 (2007)

67. N. Mohammadi, H. Khani, V.K. Gupta, E. Amereh, S. Agarwal, Adsorption process of methyl orange dye onto mesoporous carbon material-kinetic and thermodynamic studies. J. Colloid Interface Sci. $362,457-462$ (2011)

68. T. Kou, Y. Wang, C. Zhang, J. Sun, Z. Zhang, Adsorption behavior of methyl orange onto nanoporous

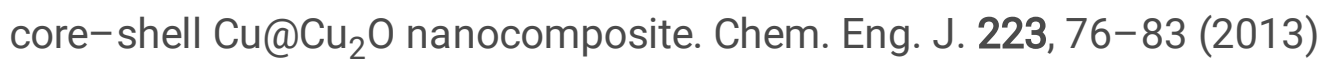

69. P. Zhang, Q. An, J. Guo, C. Wang, Synthesis of mesoporous magnetic Co-NPs/carbon nanocomposites and their adsorption property for methyl orange from aqueous solution. J. Colloid Interface Sci. 389, 10-15 (2013)

70. W. Deligeer, Y.W. Gao, S. Asuha, Adsorption of methyl orange on mesoporous $\mathrm{Y}-\mathrm{Fe}_{2} \mathrm{O}_{3} / \mathrm{SiO}_{2}$ nanocomposites. Appl Surf Sci 257, 3524-3528 (2011)

71. M. Arshadi, F. SalimiVahid, J.W.L. Salvacion, M. Soleymanzadeh, Adsorption studies of methyl orange on an immobilized Mn-nanoparticle: kinetic and thermodynamic. Rsc Adv 4, 16005-16017 (2014)

\section{Figures}



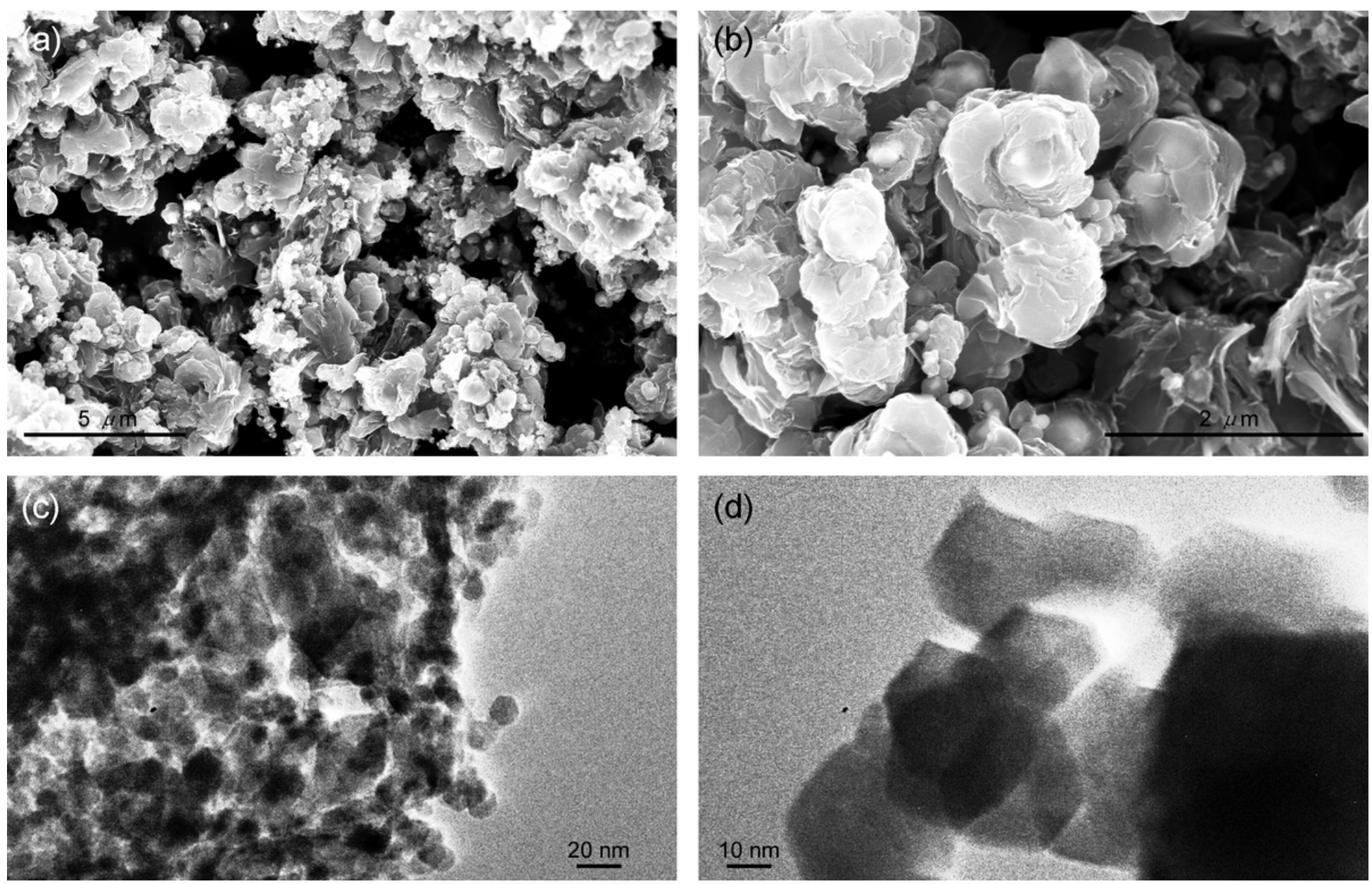

Figure 1

( $a$ and b) SEM images of C@Co; (c and d) TEM images of C@Co. 

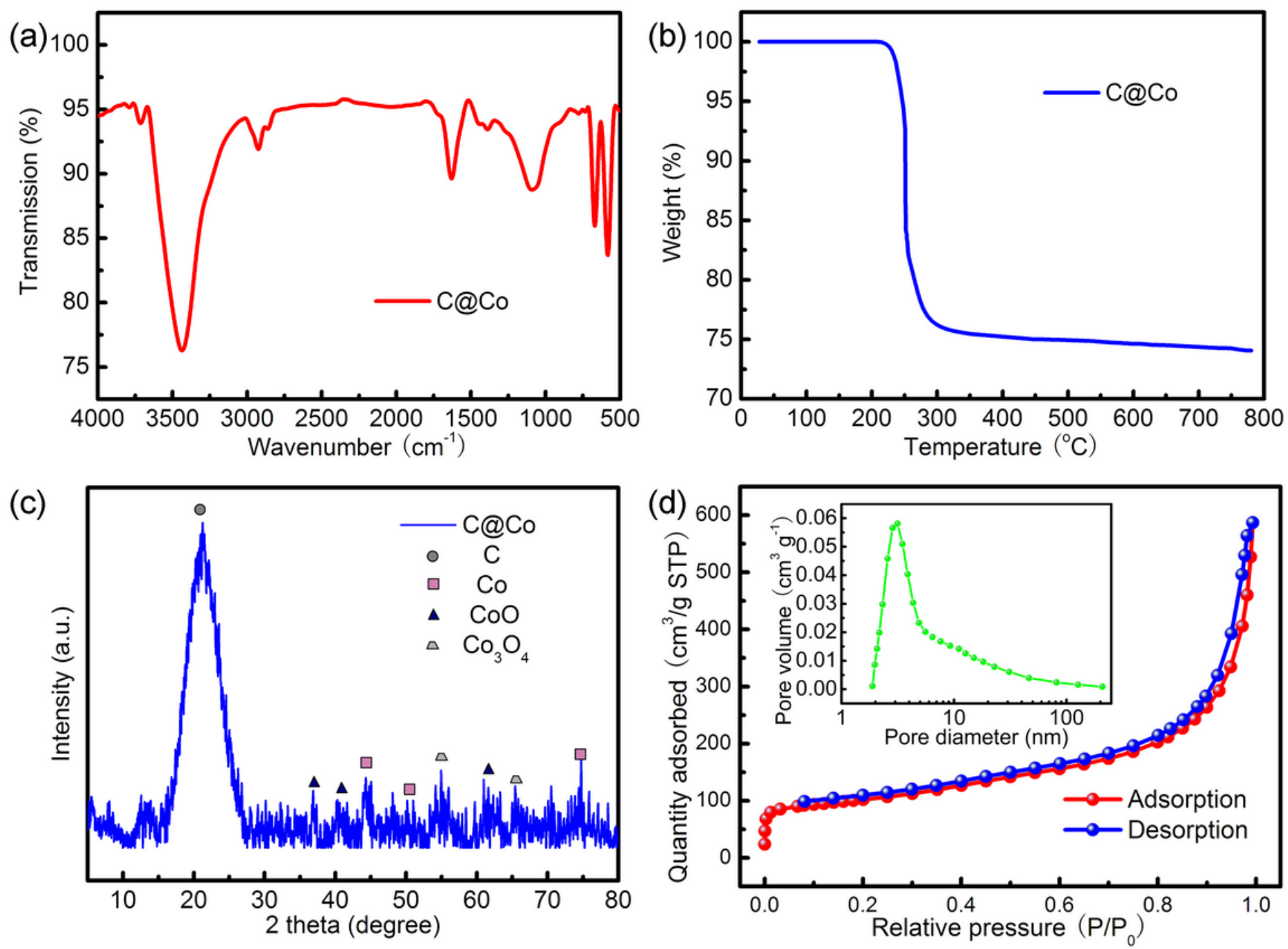

Figure 2

(a) IR spectrum of C@Co; (b) TGA curve of C@Co; (c) PXRD pattern of simulated and fresh samples of C@Co; (d) Nitrogen adsorption and desorption isotherms of C@Co. The inset shows the pore distributions. 

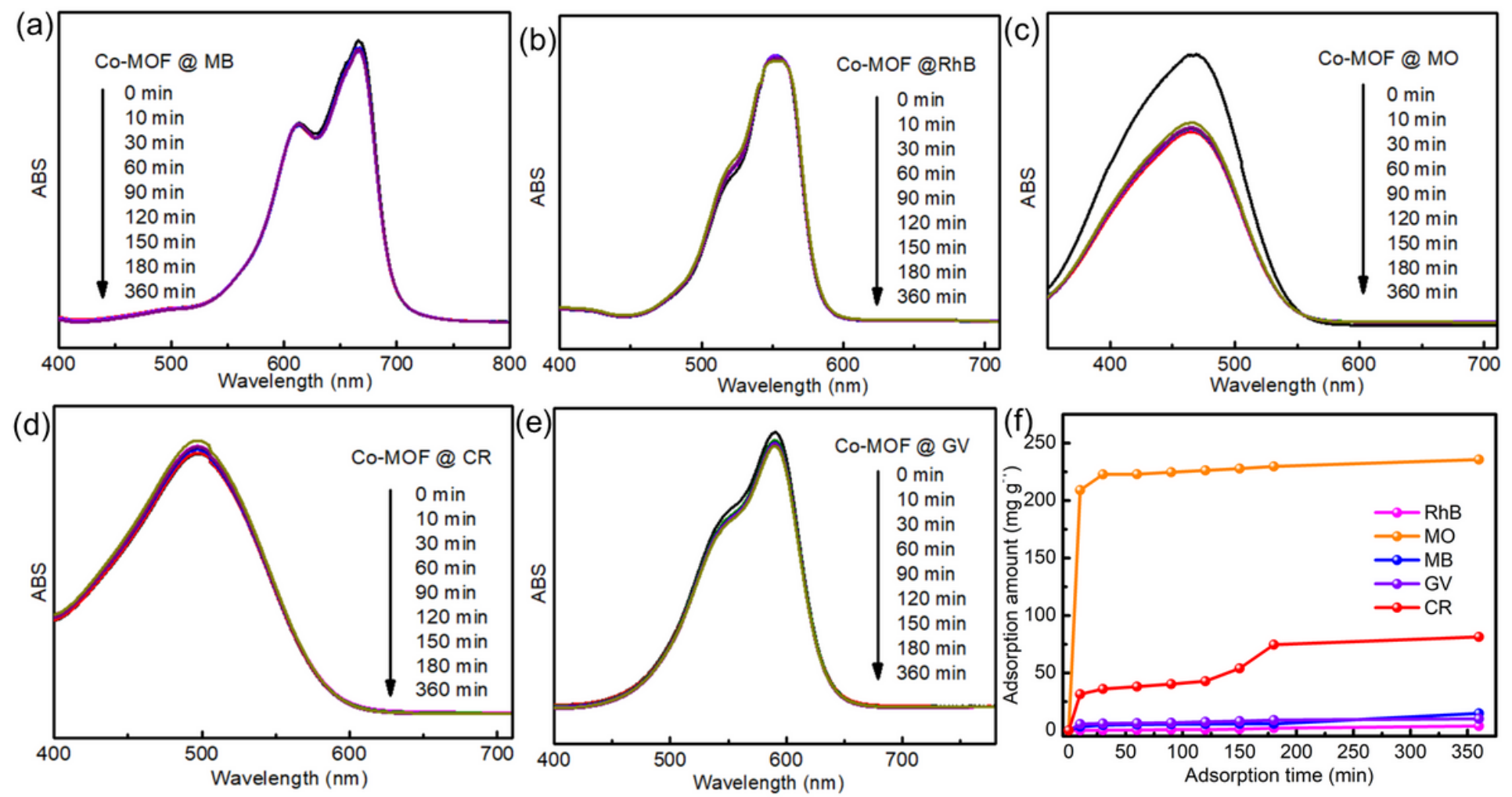

Figure 3

(a-e) UV-vis spectra of MB, RhB, MO, CR, and GV solutions after various adsorption times with Co-MOF;

(f) The capacities of MB, RhB, MO, CR, and GV absorbed from aqueous solutions by Co-MOF under similar conditions.
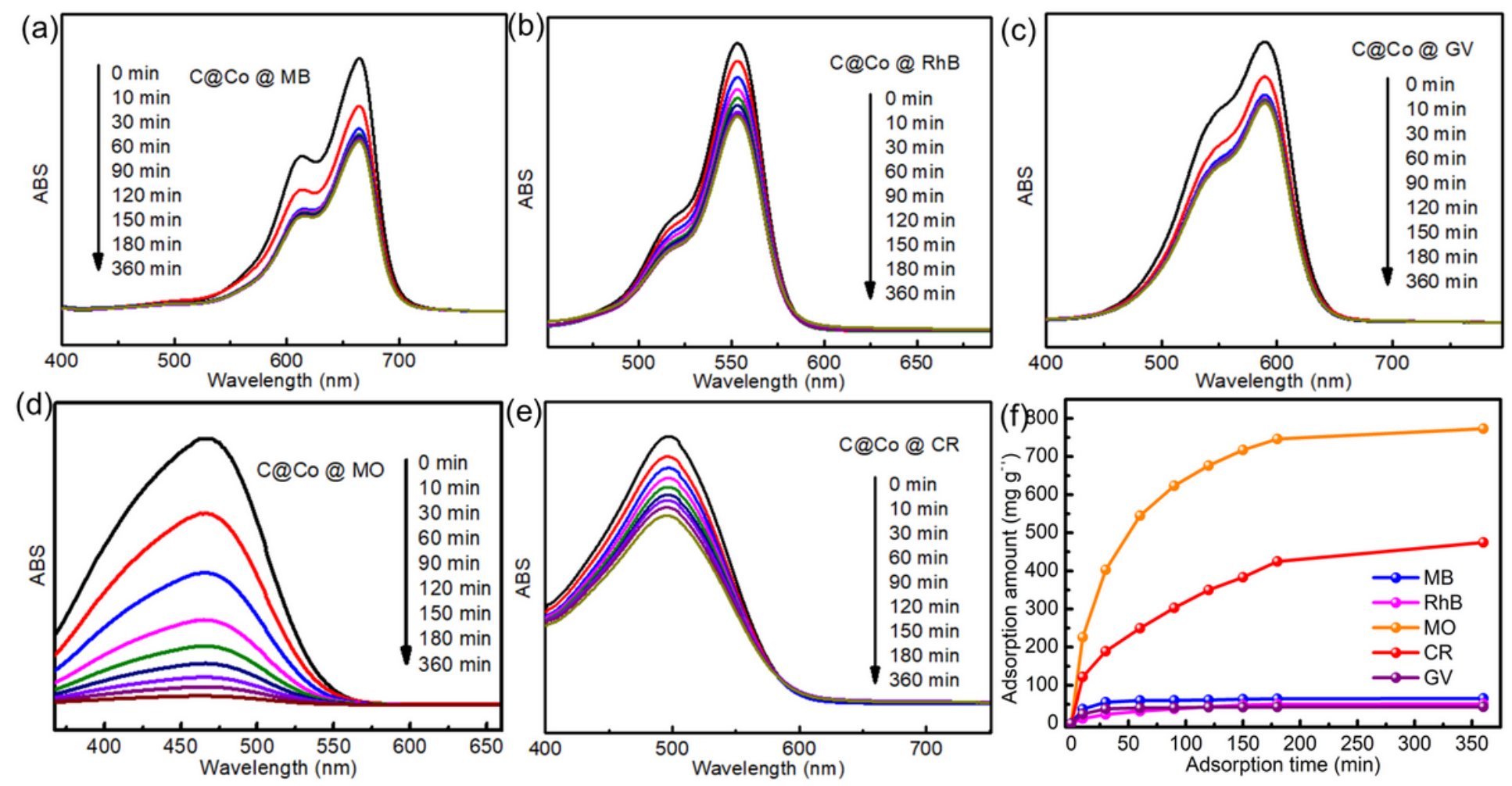

Figure 4 
(a-e) UV-vis spectra of MB, RhB, GV, MO, and CR solutions after different adsorption times with C@Co; (f) The amounts of MB, RhB, MO, CR, and GV adsorbed from aqueous solutions by C@Co under similar conditions.
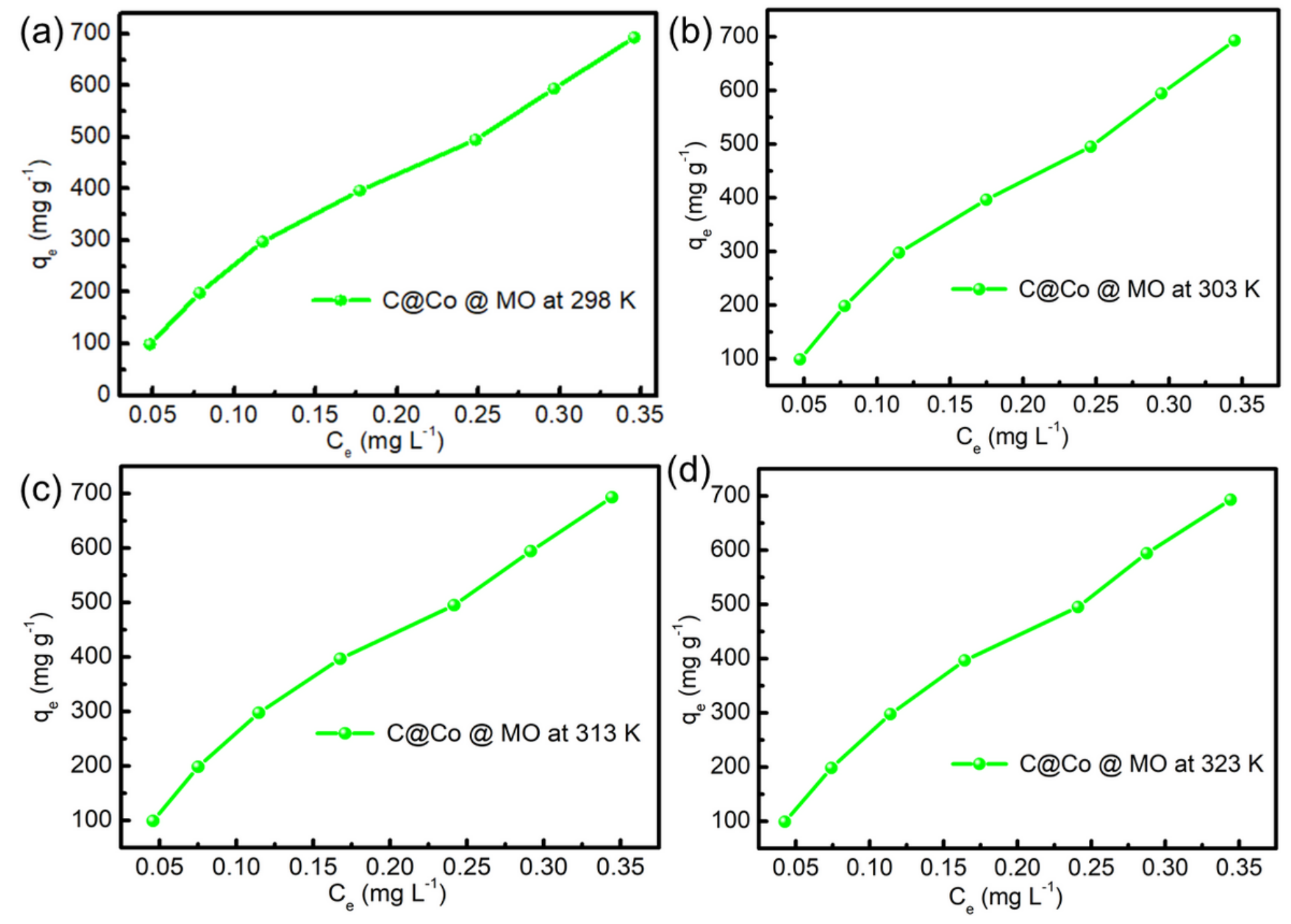

Figure 5

Effect of the temperature on MO adsorbed by C@Co. 

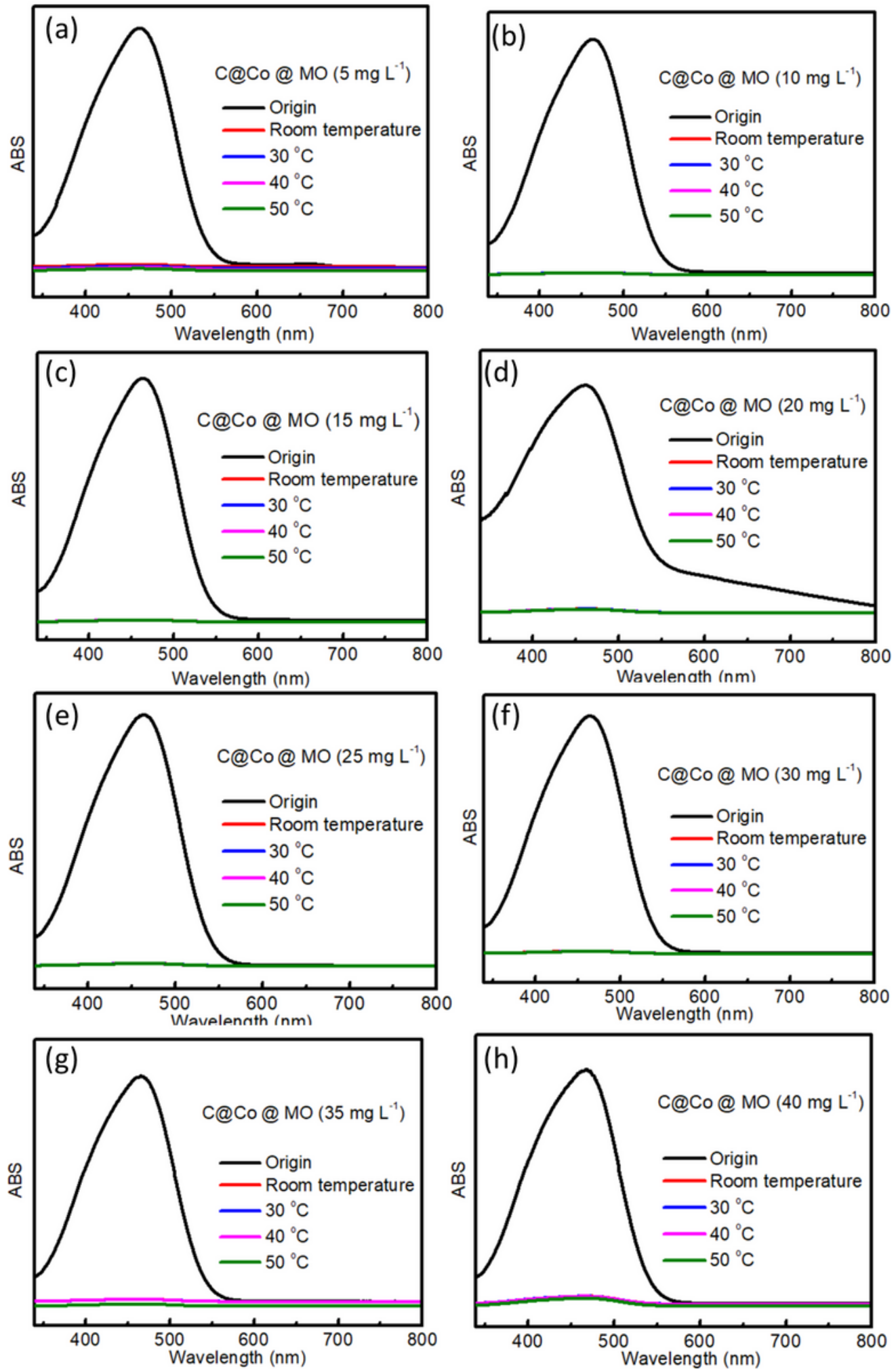

Figure 6

Effect of the concentration on MO adsorbed by C@Co. 

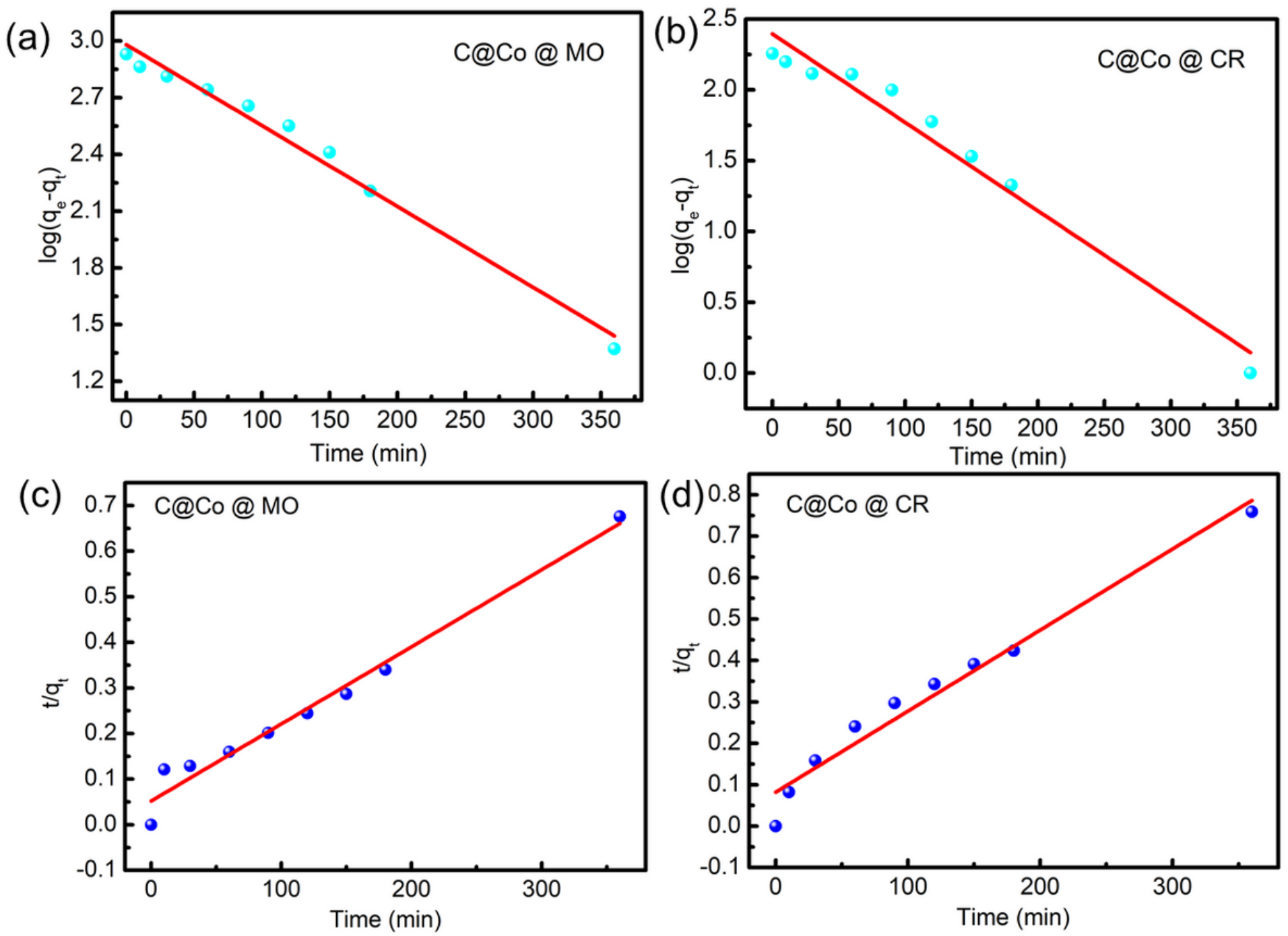

Figure 7

Adsorption kinetics of MO and CR adsorbed by C@Co: (a and b) Pseudo-first-order models; (c and d) Pseudo-second-order models.

\section{Supplementary Files}

This is a list of supplementary files associated with this preprint. Click to download.

- Checkcif.pdf

- GraphicalAbstract.doc 